\title{
Convergencia Deliberativa: La participación ciudadana en el cambio constitucional, Chile 2016
}

\author{
Pamela Figueroa Rubio \\ Universidad de Santiago de Chile, Santiago. Chile \\ Email: pamela.figueroaru@usach.cl \\ Tomás Jordán Díaz \\ Universidad Alberto Hurtado, Santiago. Chile \\ Email: tjordand@gmail.com
}

Recibido: 31.08.2020｜Ａceptado: 02.12.2020

\begin{abstract}
Resumen: Este estudio examina el caso del Proceso Constituyente Abierto a la Ciudadanía en Chile (2016), como metodología para el cambio constitucional. Las investigaciones sobre incidencia de procesos constitucionales en el resultado del texto constitucional señalan que el proceso de cambio constitucional es clave en los resultados esperados, y que las metodologías participativas deben tener ciertas características para obtener resultados (Ginsburg,et.al. 2009; Bonar, 2017; Soto \& Welp, 2019). Desde la teoría de la democracia deliberativa y de la elaboración participativa de la Constitución, el presente trabajo analiza el diseño e implementación de la etapa participativa para el cambio constitucional realizada en Chile en 2016. A través del examen de la metodología de Convergencia Deliberativa y los alcances de su implementación, se estudia la ejecución de este diseño institucional de deliberación pública como mecanismo de cambio constitucional. Este trabajo plantea que la metodología de Convergencia Deliberativa tuvo por objetivo la incidencia pública de la participación ciudadana, concebida desde una perspectiva deliberativa, considerando la participación pública incidente en todas sus etapas.
\end{abstract}

Palabras clave: Cambio constitucional; Chile; convergencia deliberativa; participación pública; incidencia ciudadana.

\section{Deliberative Convergence: Citizen Participation in Constitutional Change, Chile 2016}

\begin{abstract}
This study examines the case of the Constituent Process Open to Citizens in Chile (2016), as a methodology for constitutional change. Research on the incidence of constitutional processes in the result of the constitutional text indicates that the process of constitutional change is key in the expected results, and that participatory methodologies must have certain characteristics to obtain results (Ginsburg, et.al. 2009; Bonar, 2017; Soto \& Welp, 2019). From the theory of deliberative democracy and the participatory elaboration of the Constitution, this work analyzes the design and implementation of the participatory stage for the constitutional change carried out in Chile in 2016. Through the examination of the Deliberative Convergence methodology and the scope of its implementation, the implementation of this institutional design of public deliberation as a mechanism for constitutional change is studied. This work proposes that the Deliberative Convergence methodology had as its objective the public incidence of citizen participation, conceived from a deliberative
\end{abstract}


perspective, considering incident public participation in all its stages.

Keywords: Constitutional Change; Chile; Deliberative Convergence; Public Participation; Citizen Advocacy.

\section{Convergência deliberativa: a participação cidadã na mudança constitucional, Chile 2016.}

Resumo: Este estudo examina o caso do Processo Constituinte Aberto à Cidadania no Chile (2016), como metodologia de mudança constitucional. As pesquisas sobre a incidência de processos constitucionais no resultado do texto constitucional indicam que o processo de mudança constitucional é fundamental nos resultados esperados, e que as metodologias participativas devem ter certas características para obter resultados (Ginsburg et.al. 2009; Bonar, 2017; Soto y Welp, 2019). A partir da teoria da democracia deliberativa e da elaboração participativa da Constituição, este trabalho analisa o desenho e a implementação da etapa participativa para a mudança constitucional realizada no Chile em 2016. Por meio do exame da metodologia da Convergência Deliberativa e os alcances da sua implementação, estuda-se a aplicação deste desenho institucional de deliberação pública como mecanismo de mudança constitucional. Este trabalho propõe que a metodologia da Convergência Deliberativa visa a incidência pública da participação cidadã, concebida a partir de uma perspectiva deliberativa, considerando a participação pública incidente em todas as suas etapas.

Palavras-chave: Mudança constitucional; Chile; convergência deliberativa; participação pública; defesa do cidadão.

\section{Como citar este artículo:}

Figueroa Rubio, P y Jordán Díaz, T. (2021). Convergencia Deliberativa: La participación ciudadana en el cambio constitucional, Chile 2016. Polis Revista Latinoamericana, 20 (58), 78103. doi: http://dx.doi.org/10.32735/S0718-6568/2021-N58-1579

\section{Introducción}

El debate sobre la modificación de la actual Carta Fundamental de Chile ha estado en la agenda de actores políticos y sociales desde la promulgación de la Constitución Política en 1980. Es así, que la oposición política al régimen autoritario de Augusto Pinochet fue clara en el rechazo a una carta fundamental que fue emanada sin la más mínima garantía democrática (Fuentes, 2012). Además, desde la década de 2010 tomó fuerza de manera progresiva en organizaciones políticas, sociales, juveniles, regionales, sindicales, de género y representativas de pueblos indígenas, basados en la idea de que las reformas realizadas a la actual Constitución, si bien son un avance en algunas materias, no son suficientes para responder y satisfacer las necesidades actuales de la sociedad chilena (Heiss, 2016).

Según datos de la Encuesta de Desarrollo Humano realizada en 2013, el 76,2\% de los encuestados consideraba muy importante o bastante importante hacer cambios a la Constitución, mientras que el 65,7\% afirmaba que estos deben ser profundos. Asimismo, la 
encuesta realizada por el PNUD en 2015, en el marco del estudio Auditoria a la Democracia, que preguntó las razones para el cambio constitucional y la idea de que "sus contenidos no sirven para los desafíos del Chile actual", subió 23 puntos en comparación con la misma encuesta realizada en 2013 (de 31\% a 54\%) (PNUD, 2015a).

La demanda de cambio constitucional en Chile se da en el contexto de una crisis política institucional incipiente, representada en baja legitimidad de las principales instituciones políticas, baja participación electoral y un creciente descrédito de las élites políticas, empresariales y sociales. El informe "Auditoría a la democracia: Más y mejor democracia para un Chile inclusivo" (PNUD, 2014) señalaba que, si bien Chile avanzaba de manera significativa en el logro de objetivos democráticos, "a pesar de estos logros, la democracia en Chile aparece tensionada por el desencantamiento de la ciudadanía con la política y sus instituciones, que va más allá de una crítica puntual o de demandas específicas" (PNUD, 2014: i). Uno de los problemas evidenciados era la satisfacción con la democracia. A partir de 2010 se da una diferencia entre el apoyo a la democracia (65\%) y la satisfacción (58\%), lo que para el año 2011 es $63 \%$ y 33\%, y en $201367 \%$ y $41 \%$ respectivamente. Junto con ello, se evidencia un creciente y preocupante descenso en la confianza hacia las instituciones, tales como el gobierno, el Congreso y los partidos políticos, con $24 \%, 15 \%$ y $9 \%$ de confianza ciudadana respectivamente hacia 2012. Sin embargo, y a pesar de este desencanto con el desempeño democrático, las chilenas y chilenos mostraron apertura y adhesión a reformas políticas e institucionales,

"según datos de la encuesta LAPOP 2012, el 71\% está de acuerdo o muy de acuerdo con reformar la Constitución Política, y el $89 \%$ cree que esta reforma se debe decidir directamente a través del sufragio universal de la ciudadanía" (PNUD, 2014, p. 58).

Paralelamente, el debate constitucional en Chile se posicionó como un tema relevante durante las campañas presidenciales de 2013, donde cada candidato presentó en su programa diversos mecanismos y reformas constitucionales que abarcaban desde la proposición de modificaciones graduales o reformas parciales hasta la redacción completa de una nueva Constitución (De la República, 2013).

Es en este contexto que Michelle Bachelet gana las elecciones presidenciales en diciembre de 2013, encabezando una coalición política novedosa para la historia de Chile. La Nueva Mayoría' ${ }^{\prime}$ coalición de partidos compuesta desde la Democracia Cristiana al Partido Comunista, encarnó la demanda por un cambio sustantivo, y su amplitud permitió, por primera vez desde el retorno a la democracia, tener mayoría en ambas cámaras del Congreso. Las condiciones políticas y sociales parecían proclives al cambio constitucional propuesto por la presidenta Bachelet en su programa de gobierno (Mardones y Toro, 2014).

1 La Nueva Mayoría fue una coalición de partidos políticos constituida en Chile para las elecciones presidenciales y parlamentarias de 2013. Fue la coalición política que acompañó el segundo gobierno de Michelle Bachelet (2014-2018) 
Desde la teoría de la democracia deliberativa y de la elaboración participativa de la Constitución, el presente trabajo analiza el diseño e implementación de la etapa participativa para el cambio constitucional realizada en Chile en 2016. A través del examen de la metodología de Convergencia Deliberativa, y los alcances de su implementación durante el año 2016 en Chile, se estudia la implementación de este diseño institucional de deliberación pública como mecanismo de cambio constitucional. Este trabajo plantea que la metodología de Convergencia Deliberativa tuvo por objetivo la incidencia pública de la participación ciudadana, concebida desde una perspectiva deliberativa, considerando la participación pública incidente en todas sus etapas.

\section{Cambio constitucional y participación ciudadana}

Las teorías de democracia deliberativa y de elaboración participativa de las constituciones dan un valor central a la inclusión de mecanismos de participación ciudadana incidente como mecanismos de fortalecimiento democrático (Bonar, 2017). Desde la teoría democrática, se ha argumentado sobre la relevancia de la dimensión deliberativa de la democracia, considerando la dimensión republicana de constitución de la voluntad política y la acción comunicativa como clave en la elaboración de consensos sociales (Habermas, 2010). También se ha considerado la democracia deliberativa en procesos de cambio constitucional, ya sea la deliberación entre los representantes electos para elaborar un nuevo texto, o la democracia deliberativa como objetivo de quienes elaboran la constitución (Elster, 1998).

Los estudios comparados de procesos constituyentes han puesto énfasis en la incidencia de los procesos constitucionales en el resultado del texto constitucional, argumentando que el proceso de cambio constitucional es clave en los resultados esperados (Ginsburg, et.al. 2009; Negretto, 2015; Soto \& Welp, 2017 y 2019). Se ha argumentado, además, que si bien las condiciones y las reglas bajo las cuales se escribe, delibera y ratifica una constitución son consecuenciales, no pueden afirmar en qué medida y de qué manera lo hacen. La literatura fue creciendo en cuanto a estudios de caso que analizan conceptualización

y medida de los procesos, y eso da relevancia a la metodología de estudios de caso para contrastar las teorías de los efectos de democracia deliberativa en los procesos de cambio constitucional. Se considera, que la variación en la legitimidad del cambio constitucional está dada por los niveles de inclusión de diversos actores de la sociedad, así cómo por el momento en que los ciudadanos y ciudadanas son incluidos en el proceso constituyente (Ginsburg,et.al. 2009).

A razón de la Primavera Árabe, diversos estudios analizaron cómo los países que desarrollaban procesos constitucionales post-conflicto y transicionales, dieron espacios importantes a la participación ciudadana, con el objetivo de llegar a las bases del conflicto, y asegurar de esta forma un consenso duradero. (Gluck and Brandt, 2015, p. 5)

Las experiencias internacionales de participación ciudadana en procesos constituyentes son acotadas, y existe registro sobre el tipo de participación, el procedimiento, pero no 
de los resultados de la participación pública que permita identificar de manera trazable la incidencia de dicha participación. En el período 1970 y 2018, Soto y Welp identifican veintinueve casos en veintisiete países donde hay procesos participativos asociados a cambio constitucional en distintas modalidades. De acuerdo con los autores, si bien de manera creciente los procesos de cambio constitucional consideran la participación pública, no está claro cuáles debieran ser los criterios para considerar estos procesos "justos y democráticos" (Soto y Welp, 2019).

Por otra parte, organismos intergubernamentales venían desarrollando estudios comparados para encontrar buenas prácticas de participación en las políticas públicas, como una forma de abordar los problemas de confianza en las instituciones públicas, lo que ya venía mostrando problemas de gobernanza y gobernabilidad democrática. Es asi que la Organización para la Cooperación y el Desarrollo Económicos (OCDE) ha determinado ciertos estándares de participación pública, basados en criterios mínimos para procesos participativos democráticos, entre los que se mencionan: a) definición clara de tareas, b) representación, c) accesibilidad a los recursos, d) estructuración de la elaboración de las decisiones, e) independencia, f) transparencia, g) influencia y h) costo-efectividad (OECD, 2005). Por otra parte, se afirma que "iniciar un Proceso Constituyente a través de un proceso participativo plantea la cuestión de la democracia y sus diferentes dimensiones" (OCDE, 2017, p. 3). IDEA Internacional, a través de su programa de elaboración de constituciones, ha prestado apoyo técnico a los procesos de cambio constitucional a nivel global, así también en Chile (IDEA, 2020).

\section{Aproximación metodológica}

La presente aproximación a la perspectiva de la democracia deliberativa y la elaboración participativa de las constituciones aborda el caso del Proceso Constituyente Abierto a la Ciudadanía implementado en Chile en 2016, durante el gobierno de la presidenta Michelle Bachelet. El estudio de casos es relevante para el examen de los procesos de cambio constitucional (Ginsburg et.al., 2009). A través del examen de la metodología de Convergencia

Deliberativa, y los alcances de su implementación, se estudia la ejecución de un diseño institucional de deliberación pública como mecanismo de cambio constitucional. El trabajo se sustenta en el análisis de documentos oficiales de diseño e implementación del proceso, en las estadísticas del proceso participativo, revisión de las actas de las distintas instancias del proceso, notas de reuniones del Ministerio Secretaría General de la Presidencia y de los equipos internos de gobierno involucrados en esta política pública, del Consejo Ciudadano de Observadores, del Comité de Sistematización, la participación en seminarios nacionales e internacionales, y la participación observante en Encuentros Locales Auto-convocados, Cabildos Provinciales y Regionales. 


\section{Resultados \\ Diseño Del Proceso Constituyente Abierto A La Ciudadanía Antecedentes Del Cambio Constitucional En Chile}

El cambio constitucional en Chile ha sido una demanda que surge junto a la instauración de la Constitución Política bajo la dictadura cívico-militar en 1980. La procedencia autoritaria y los dispositivos constitucionales contra-mayoritarios de la actual Constitución han sido una de las grandes razones del cuestionamiento a la legitimidad de origen de ésta (Atria, 2013 y 2017). El origen autoritario, define un texto constitucional que desconfía de la política, de la ciudadanía, y establece enclaves autoritarios para asegurar la implementación de un modelo político y de desarrollo (Garretón, 1995, Eyzaguirre, et.al 2020). La propia Constitución estableció la mayor de las trabas, que es la imposibilidad de elaborar un nuevo texto constitucional.

Las presiones de los demócratas para acometer el cambio Constitucional han ido marcando hitos fundamentales en el desarrollo político de Chile. En 1989 el primer paquete de cambios constitucionales permitió las condiciones mínimas de pluralismo y transparencia para la transición. En 2005, el presidente Ricardo Lagos impulsa un segundo paquete de reformas constitucionales, que buscaron eliminar los llamados "enclaves autoritarios" y así consolidar la democracia. Estas reformas se hicieron a través del Congreso, el cual ha sido definido como un constituyente "atípico". Más que acordar los ejes constituyentes básicos, fue desencajando las imposiciones del constituyente originario-autocrático, conformando una Constitución distinta a la original, pero por destrabamiento. El efecto ha sido una Constitución sin pilares político-jurídicos claros, comunes o compartidos. No es una Constitución producto de acuerdos políticos y sociales amplios (Jordán, 2014).

El triunfo electoral de Michelle Bachelet en 2013 inició el camino para el primer intento institucional de cambio constitucional en Chile. La presidenta manifestó su voluntad de elaborar una nueva Constitución nacida en democracia, con instancias reales de participación ciudadana y dentro de los canales de la institucionalidad. De una forma inédita en la historia constitucional de Chile, la propuesta de cambio constitucional presentada por Bachelet se denominó Proceso Constituyente Abierto a la Ciudadanía, por incluir la participación pública como eje central de su desarrollo.

\section{El Proceso Constituyente Como Un Ejercicio De Participación Política Deliberativa}

El mandato presidencial de un proceso democrático, participativo e institucional2 ${ }^{2}$ tenía un doble desafío: las dificultades institucionales de la propia Constitución que no consideraba un mecanismo de reemplazo total, y la casi nula experiencia de procesos participativos nacionales e incidentes en Chile. Con este mandato y antecedente institucional, el diseño

2 Para mayor detalle, ver: Programa de Gobierno Michelle Bachelet 2014-2018 [recurso electrónico] / Michelle Bachelet. [Chile]: [Editor no identificado], 2013. 1 archivo electrónico (198 páginas): digital, formato PDF . 
metodológico se pensó en base a la incorporación de mecanismos de democracia deliberativa, que, canalizando la demanda ciudadana por el cambio constitucional, fortaleciera la valoración de la democracia y el compromiso presidencial. Las democracias liberales occidentales, tienden a ser fuertes en mecanismos de representación, no así en mecanismos de participación y deliberación ciudadana (Habermas, 2005). El caso de Chile no era diferente, y la creciente desconfianza hacia las instituciones políticas era muestra de ese déficit democrático (PNUD, 2015).

La Constitución es un pacto de convivencia pacífica que establece los límites y vínculos con el poder político ${ }^{3}$. Ante esto, el proceso constitucional, como elaboración de una política, requiere la participación de la ciudadanía, siendo los gobiernos garantes de la participación al asegurar la disponibilidad de información objetiva e igualdad de los ciudadanos a la hora de participar (OECD, 2001).

La participación política es definida como la intervención de la sociedad civil en la esfera de lo público, lo cual no necesariamente se limita a los procesos electorales sino representa también una forma de participar, controlar y moderar el poder otorgado a los representantes políticos a través de formatos y mecanismos de participación ciudadana, que fortalezcan y nutran la vida democrática de la sociedad (Cunill, 1991).

El Proceso Constituyente se definió como Abierto a la Ciudadanía, por cuanto se instituye como un mecanismo de cambio constitucional que incorpora la discusión pública con los ciudadanos sobre los asuntos constitucionales, permitiendo el diálogo y la convergencia para la construcción de acuerdos de las personas sobre la Constitución, registrando los acuerdos parciales o desacuerdos entre ellos. El mecanismo de cambio constitucional tiene dos elementos distintivos: "mecanismos de participación pública incidente antes del momento de deliberación constitucional y la concurrencia de los poderes co-constituyentes (Presidencia de la República y Congreso)" (Jordán y Figueroa, 2020, p. 231-232).

La idea de deliberación pública racional tiene un momento de discurso, otro de negociación y un tercero de solución (Habermas, 2010). Adicionalmente, se debe dar la cooperación en ese espacio público deliberativo. Ésta permite el intercambio (diálogo) en el cual los participantes se benefician del encuentro, pues logran algo que no podrán obtener individualmente (Sennet, 2012). En la cooperación no sólo concurren personas con intereses semejantes sino diferentes, incluso en conflicto, buscando el equilibrio entre cooperación y competencia. La cooperación busca disminuir la competencia agresiva, gestionando las diferencias de difícil tratamiento como un acuerdo de convivencia colectiva.

3 Ferrajoli, L. Entrevista en Expertos en Estudio: El rol de las constituciones. [Consultado 30 agosto 2020]- Disponible en: https://www.youtube.com/watch?v=S1ykTjUqcR8 


\section{La Convergencia Deliberativa Como Metodología de Generación de Acuerdos Constitucionales}

Se propuso para la deliberación pública una metodología especial, diseñada por el Gobierno4, para el desarrollo de las conversaciones constitucionales. La Convergencia Deliberativa concibe el proceso como un espacio mediante el cual las personas desarrollan conversaciones (deliberación) a partir de distintas posiciones, y llegan a conclusiones o puntos en común (convergencia), de manera colaborativa, para definir acuerdos, acuerdos parciales o desacuerdos sobre los asuntos constitucionales 5 .

La convergencia deliberativa tiene dos componentes: la convergencia entendida como acto de cooperación para la búsqueda de puntos en común, y la deliberación, entendida como el diálogo a partir de distintas posiciones, evaluando las ventajas y desventajas, en la construcción de acuerdos o decisiones. Deliberar es reflexionar colectivamente sobre alternativas para tomar una decisión conjunta y configurar un acuerdo. Esta combina elementos conceptuales, como la cooperación y la legitimidad; elementos metodológicos, como el diálogo en torno a temáticas concretas con el apoyo de los facilitadores, y elementos simbólicos de encuentro, cohesión y experiencia de logro compartida.

En este concepto es central la idea sobre la construcción de un acuerdo. El acuerdo implica buscar el encuentro de aquello que comparten, dos o más partes, poniendo en común ideas $u$ objetivos. Es la construcción de posiciones comunes identificando y ensamblando las opiniones de los participantes. El acuerdo se logra a través del debate y/o conversación, en el que los participantes exponen sus argumentos buscando los elementos compartidos. Construir acuerdo considera tareas cognitivas como reconocer el argumento de las otras personas, considerar estos argumentos como razonables y ceder un lugar para ellos en las conclusiones, lo que se realiza mediante el ejercicio de diálogo y en pos de los objetivos comunes. De igual manera, el reconocimiento de los acuerdos conlleva otorgar valor

\footnotetext{
4 En la elaboración de la metodología de convergencia deliberativa participó un grupo multidisciplinario entre los que estuvieron la politóloga Pamela Figueroa, los psicólogos Carolina Gómez y Miguel Jofré, el sociólogo Rodrigo Araya y el abogado Tomás Jordán. Esta metodología fue sometida al examen y comentarios del Consejo Ciudadano de Observadores, órgano cuyos integrantes fueron nombrados especialmente por la Presidenta Michelle Bachelet para fiscalizar el fiel cumplimiento de la metodología.

5 Se entendió por Acuerdo, Acuerdo Parcial y Desacuerdo lo siguiente: Acuerdo. Se produce cuando los participantes consideran que un valor, un principio, un derecho, un deber, una responsabilidad o una institución debe inspirar y dar sustento, o establecerse para todas las personas, o ser considerado en la Constitución Política de la República. Un acuerdo valora los puntos que tienen en común las personas que participan en el grupo. Se desarrolla como la búsqueda de los elementos que los unen. Acuerdo Parcial. Se produce cuando los participantes consideran que un valor, un principio, un derecho, un deber, una responsabilidad o una institución debe inspirar y dar sustento, o establecerse para todas las personas, o ser considerado en la Constitución Política de la República, pero tiene distintos argumentos o razones para ello. Un Acuerdo Parcial permite a los grupos explicar las distintas acepciones de un concepto y las distintas visiones que las personas tienen sobre él, evitando trabar la conversación cuando existe una voluntad común para que el concepto esté en la Constitución Política. Desacuerdo. Se produce cuando un término mencionado en la conversación no concita apoyo para inspirar y dar sustento, o establecerse para todas las personas o considerar en la Constitución Política de la República. Un Desacuerdo permite marcar o mostrar con claridad posiciones divergentes (distintas), como también puede destrabar puntos rígidos entre los participantes (cuando el diálogo se inmoviliza o dificulta). SEGPRES (2017). Guía Metodológica para el Proceso Constituyente.
} 
a los acuerdos de orden parcial o los desacuerdos en un proceso de diálogo. Se reconoce que estos acuerdos pueden ser parciales o simplemente pueden existir desacuerdos entre los participantes.

\section{La idea de participación pública incidente como sostén del Proceso Constituyente y de fortalecimiento de la democracia}

El modelo incorporó la participación ciudadana incidente. Ésta tiene dos elementos que la componen: la incidencia como influencia en las decisiones públicas y la incidencia como fortalecimiento del mandato de representación. De esta manera la incidencia se logra por medio de la convergencia deliberativa (no es la mera declaración de diversas posiciones constitucionales), expresada en los acuerdos en los distintos niveles participativos expresados en las Bases Ciudadanas. Estas Bases son el punto sobre el cual se trabajarán los contenidos constitucionales, adicionados y complementados con los distintos aportes que el debate constitucional ha aportado en los últimos años. La incidencia es un elemento propio del diseño de la Etapa Participativa que contiene un compromiso de orden político en que ello se ejecute. En la incidencia hay responsabilidad política involucrada que es manifestación de la potestad co-constituyente.

La incidencia tiene un efecto en el sistema político que es el fortalecimiento de la democracia representativa (Bobbio, 1986). Es decir, la participación pública incidente provee contenidos (las visiones constitucionales de las personas) y fortalece el ejercicio de la representación, al instaurar un mandato con responsabilidad política, el cual exige considerar los resultados de la participación pública.

Las Bases Ciudadanas producen incidencia en dos tiempos constitucionales. El primero al constituir el documento que activa la incidencia y en el proyecto de cambio constitucional es su expresión. Luego, el proyecto al ser discutido en la sede constituyente elegida, sus contenidos producirán la segunda incidencia sobre los actores que serán parte integrante del órgano constituyente. Esto es parte de la devolución a la ciudadanía y trazabilidad de las Bases Ciudadanas y el proyecto de cambio (Jordán y Figueroa, 2020).

\section{Etapa participativa del proceso constituyente abierto a la ciudadanía}

La Etapa Participativa del Proceso Constituyente Abierto a la Ciudadanía se refiere a la participación y diálogos ciudadanos, realizados entre el 23 de abril y el 6 de agosto de 2016 , donde se debatió sobre asuntos constitucionales. El Proceso Constituyente Abierto a la Ciudadanía consideró tres grandes momentos: el Encuentro, la Deliberación y la Soberanía. Cada uno de estos momentos constitucionales consideraba un resultado que permitiera identificar la incidencia de la participación ciudadana: Bases Ciudadanas, texto de nueva Constitución, nueva Constitución sancionada (Figura 1). 
Figura 1.

Momentos del Proceso Constituyente Abierto a la Ciudadanía

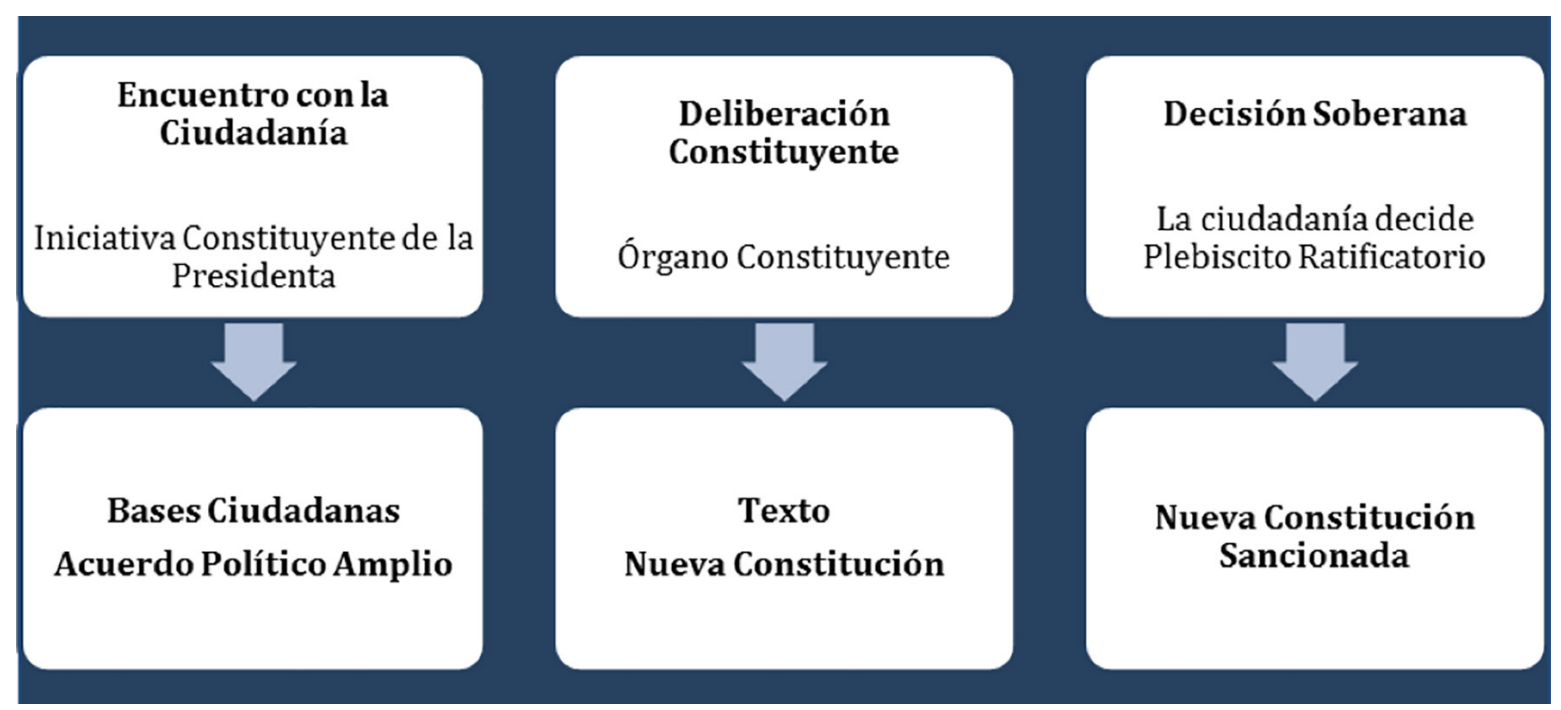

Fuente: Ministerio Secretaría General de la Presidencia

Como se puede apreciar en la figura 1, el diseño general del proceso introduce un foco esencial en la participación. El objetivo de los tres momentos -Encuentro, Deliberación y Soberanía- apunta a establecer una relación transversal y permanente entre Estado, Gobierno y Sociedad, mediante la generación de instancias de participación propiciadas por el Gobierno para la elaboración de nuevos acuerdos o consensos sociales respecto de las reglas que deben regir nuestra vida en sociedad.

En el primer momento -el Encuentro- la participación incidente permite configurar los temas que son prioritarios para la ciudadanía en un nuevo texto constitucional. En el segundo momento -la Deliberación- si bien la discusión del proyecto estará radicada en el órgano constituyente que se defina, la participación ciudadana será una exigencia permanente de la sociedad y tendrá como eje el seguimiento y fiscalización de los avances del proyecto y de la inclusión de las visiones de la ciudadanía. Finalmente, el tercer momento -la Soberanía- es el punto cúlmine del proceso, en donde la sociedad deberá definir, mediante un plebiscito, si aprueba el proyecto de nueva Constitución.

Durante el Gobierno de la presidenta Michelle Bachelet, se desarrolló el momento del Encuentro, que dio como resultado las Bases Ciudadanas ${ }^{6}$ para la Nueva Constitución. Este documento es la base del proyecto de cambio Constitucional que la Presidenta Michelle Bachelet envió al Congreso Nacional en marzo de 20187. Además, se generaron las condiciones para iniciar el momento de la Deliberación, a través de la presentación de la

6 El documento Bases Ciudadanas, se compone de tres partes: una sistematización del resultado de los distintos niveles de participación; una sintesis de la sistematización de resultados realizada por el Consejo Ciudadano de Observadores; y un informe de observación a cargo de este mismo órgano.

7 El Proyecto de reforma constitucional, iniciado en mensaje de S.E. la Presidenta de la República, para modificar la Constitución Política de la República. Mensaje № 407-365, Boletín № 11.617-07, fue ingresado el 6 de marzo de 2018. https://svconstitucional.senado.cl/assets/documentos/mensaje.pdf 
reforma al Capítulo XV8 de la Constitución actual, que permitiría, la completa modificación de la Constitución y determinará la sede constitucional en la que se elaborará su texto definitivo. Finalmente, un nuevo Congreso Nacional debería promover el momento de la Soberanía donde la ciudadanía ratifica mediante plebiscito la Nueva Constitución.

Un instrumento de trazabilidad entre el texto constitucional presentado al Congreso por la presidenta Michelle Bachelet, y las actas de los Encuentros Locales, identifica noventa (90) prioridades de las Bases Ciudadanas que se encuentran en el proyecto de Nueva Constitución, ello, entre elementos nuevos y actualmente vigentes pero que fueron parte de la deliberación pública de 20169. Este instrumento fue elaborado por la División de Estudios del Ministerio Secretaría General de la Presidencia, y es público mediante la plataforma Tableau.

\section{La Participación Territorial}

La Ełapa Participativa del Proceso Constituyente fue diseñada con un énfasis territorial, de manera que los niveles de participación previos organizaran, priorizaran y definieran la agenda de las conversaciones de etapas siguientes. Estos fueron: el Nivel Local, Provincial y Regional. Los contenidos surgidos de los diálogos ciudadanos, una vez realizados los tres niveles de participación, fueron sistematizados y constituyen las Bases Ciudadanas para la Nueva Constitución. Estas son el insumo para que la presidenta elabore y envíe un proyecto de cambio constitucional al Congreso Nacional. El diálogo en cada uno de estos niveles se realizó mediante preguntas orientadoras derivadas de los temas constitucionales de deliberación (Guía Metodológica).

La convergencia deliberativa se produce a través de los distintos niveles territoriales de participación, es decir, los acuerdos logrados en las etapas previas organizan, priorizan y definen la agenda de las conversaciones de etapas siguientes, tal como se aprecia en la figura 2.

8 La reforma al Capítulo XV ingresada por la Presidenta Michelle Bachelet se retoma en diciembre de 2019, luego del Acuerdo por la Paz y la Nueva Constitución, desde donde se tramita la propuesta de la Mesa Técnica del Proceso Constituyente para definir el itinerario constitucional hoy en curso.

9 Ver la trazabilidad de las Bases Ciudadanas en el siguiente link: https://public.tableau.com/profile/jose.chavez\#!/ vizhome/PlataformalnfograficaPROCO/Introduccin 
Figura 2.

Diagrama de la Etapa Participativa del Proceso Constituyente

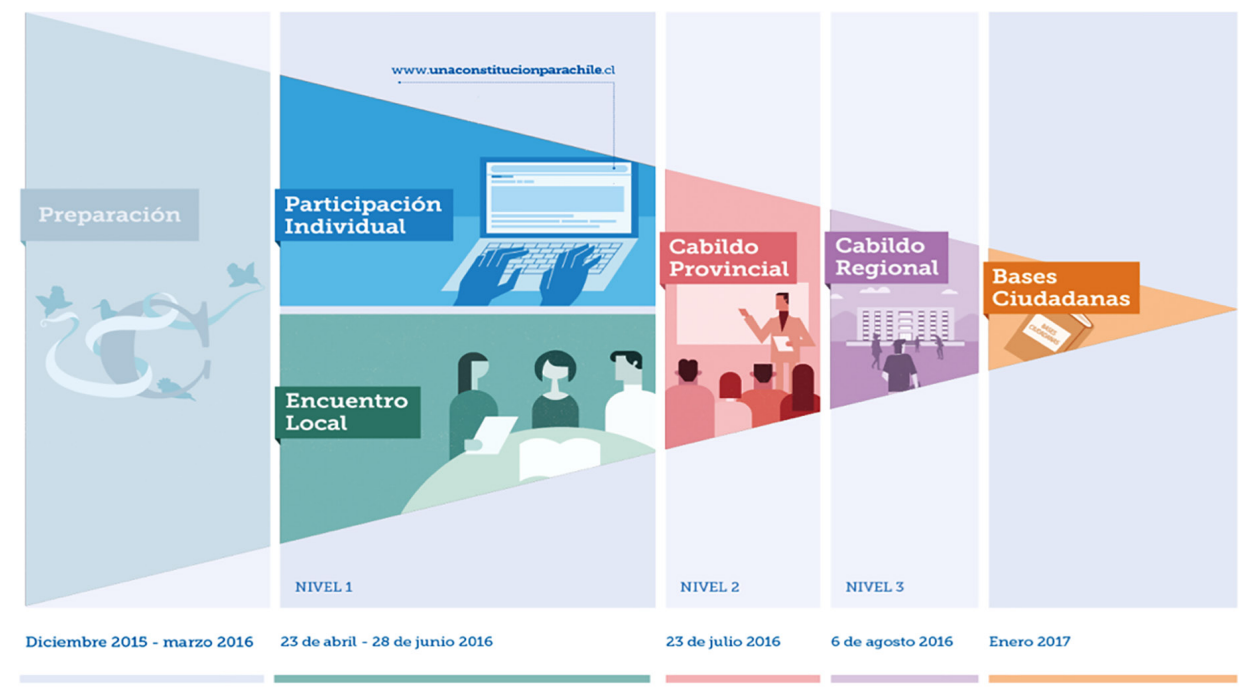

Fuente: Ministerio Secretaria General de la Presidencia. Guía Metodológica.

\section{Campaña pública de educación, información y motivación}

La realización del proceso participativo requirió entregar a la ciudadanía información clara, imparcial y motivadora para que los ciudadanos y ciudadanas puedan ser parte de las conversaciones del proceso participativo. De esta forma se desarrolló una campaña pública que entrega información a los ciudadanos y los motiva a ser parte del proceso. El diseño de esta campaña se realizó juntamente con el diseño metodológico, considerando desde el inicio los contenidos a implementar durante los distintos niveles participativos ${ }^{10}$. Los objetivos de la campaña fueron: a) establecer una línea base para el diálogo, por medio de la difusión de aquellos conceptos básicos para generar conversaciones constitucionales en las distintas formas y niveles del proceso participativo (www.constitucionario.cl) y b) informar y motivar la participación de la ciudadanía en las diferentes formas y niveles del proceso participativo (cómo, cuándo y dónde participar).

La campaña de información sobre la etapa participativa tuvo como objetivo informar sobre las formas de participar generando acciones para dar a conocer las instancias, su metodología, días y toda aquella información que facilite la participación en el proceso. De esta manera, se desarrolló en distintos formatos (redes sociales, radial, televisión, impresos y otros), mensajes para convocar y explicar el proceso a la ciudadanía. La campaña también tuvo un rol motivador para la participación. Mediante micro-documentales sobre

10 Para el diseño de la campaña comunicacional se contó con la asesoría de los destacados publicistas Martín Vinacur y Victoria Massarelli. Junto con ello, la implementación y complemento de la campaña la realizó Secretaría de Comunicaciones del Gobierno de Chile. 
personas que participaron en los Encuentros Locales y los efectos positivos que resultan de ello, se intenta estimular la participación en los distintos niveles de participación. Estos documentales son difundidos y dispuestos en www.tomolapalabra.cl.

\section{Actores De La Etapa Participativa}

La Ełapa Participativa del Proceso Constituyente fue una política pública que convocó a todos los sectores políticos y sociales, de tal manera que en su diseño consideró la representación de actores tanto institucionales como sociales, quienes colaboraron en su diseño y ejercieron un rol fundamental durante su implementación.

La incorporación de actores sociales como co-ejecutores del proceso junto con el Gobierno surge de la necesidad de recuperar la confianza de la ciudadanía en las políticas públicas. El Gobierno realizó un diagnóstico que describe un creciente ánimo de desconfianza de la ciudadanía con las instituciones públicas y privadas, lo que pone un desafío mayor al proceso, considerando su naturaleza participativa. El Gobierno se hace cargo de este diagnóstico mediante un diseño donde diversos actores institucionales y sociales son parte fundamental y, a su vez, otorgan legitimidad al proceso.

A partir de lo anterior, se promovió la incorporación de distintos actores, desde diversos ángulos en la Ełapa participativa, tales como la participación directa y deliberativa, la observación y fiscalización del proceso, y la canalización de los resultados en cada una de las etapas y decisiones relativas a éste. La relación y desempeño de los distintos actores funcionó sobre la base de la colaboración entre las partes, distinguiendo los roles de cada uno.

\section{Colaboración entre el Gobierno, ciudadanía, Consejo Ciudadano de Observadores y Comité de Sistematización para el avance de la Etapa Participativa}

Para llevar a cabo la Etapa Participativa, se diseñó un modelo donde interactuaron distintos actores que otorgan legitimidad y autonomía al desarrollo de los diálogos ciudadanos y los contenidos que surgen de éstos. Es así como el gobierno fue el encargado de proponer el diseño metodológico, llevar a cabo la campaña pública de información cívica-constitucional y de información de la etapa, así como la producción de los cabildos provinciales y regionales a través de las Gobernaciones e Intendencias. La ciudadanía es el actor central y es asesorada y acompañada metodológicamente por facilitadores. Los diálogos ciudadanos son sistematizados por el Comité de Sistematización -autónomo y externo al Gobierno- y el proceso, en todas sus partes, es observado por el Consejo Ciudadano de Observadores, compuesto por personas con una amplia trayectoria académica, social o de representación de la sociedad. 


\section{El Consejo Ciudadano de Observadores}

Nombrado por la presidenta de la República en diciembre de 2015. Estuvo compuesto por 15 consejeros ${ }^{11}$ con amplia trayectoria académica, social o de representación de la sociedad $^{12}$. El Consejo fue presidido por Patricio Zapata y constituido por Benito Baranda, Jean Beausejour, Roberto Fantuzzi, Arturo Fermandois, Patricio Fernández, Francisco Fernández, Gastón Gómez, Hernán Larraín, Héctor Mery, Salvador Millaleo, Ruth Olate, Juanita Parra, Lucas Sierra y Francisco Soto.

En virtud de su mandato, el Consejo Ciudadano de Observadores (CCO) realizó funciones en las siguientes acciones de la Etapa Participativa:

- Selección del Equipo de Facilitadores.

- Jornada Nacional de Capacitación de Facilitadores.

- Audiencias Públicas.

- Recepción de denuncias y consultas.

- Observación de los niveles de participación.

- Elaboración del Informe Final.

De igual forma, entre los días 23 de abril y 28 de junio de 2016 el CCO concurrió a un total de 89 Encuentros Locales de más de 15.000 inscritos. Durante ese período, los consejeros realizaron un despliegue territorial en siete regiones del país, más un Encuentro Local realizado por chilenos residentes en la ciudad de Barcelona, España.

Figura 3.

Número de Encuentros Locales Autoconvocados observados según miembros del Consejo

\begin{tabular}{|l|l|}
\hline Consejero & Número de Encuentros Locales \\
\hline Benito Baranda & 21 \\
\hline Roberto Fantuzzi & 20 \\
\hline Francisco Soto & 11 \\
\hline Juanita Parra & 11 \\
\hline Salvador Millaleo & 10 \\
\hline Hernán Larraín & 10 \\
\hline Patricio Fernández & 9 \\
\hline Patricio Zapata & 5 \\
\hline Héctor Mery & 4 \\
\hline Francisco Fernández & 2 \\
\hline Gastón Gómez & 2 \\
\hline Lucas Sierra & 2 \\
\hline Jean Beasejour & 1 \\
\hline Ruth Olate & 0 \\
\hline Arturo Fermandois & 0 \\
\hline
\end{tabular}

Fuente: elaboración propia en base a información proporcionada por el Consejo Ciudadano de Observadores

11 Se nombraron originalmente 17 consejeros. José Miguel García y Cecilia Rovaretti no continuaron su participación. 12 Consejo Ciudadano de Observadores [El línea]. [Consultado 15 julio 2017]. Disponible en:-https://www.ccobservadores.cl/ 
El Consejo Ciudadano de Observadores desarrolló sus labores desde su constitución, el día 2 de diciembre de 2015, hasta el cese de su mandato el día 16 de enero de 2017, en que hizo entrega del Informe Final sobre el proceso de participación y diálogos constitucionales, componente fundamental de las Bases Ciudadanas.

\section{El equipo territorial de facilitadores}

Para la coordinación y asesoría metodológica de los Encuentros Locales, y la conducción metodológica de los Cabildos Provinciales y Regionales se contó con equipos territoriales de facilitadores. Estos profesionales fueron seleccionados mediantes el Sistema de Alta Dirección Pública del Servicio Civil y contratados por la Secretaría General de la Presidencia para desarrollar diferentes funciones. Durante la etapa local los facilitadores tuvieron como función principal el acompañamiento directo a los organizadores de Encuentros Locales Autoconvocados, asesorándolos en aspectos metodológicos y operativos. Durante la etapa provincial y regional, los facilitadores tuvieron la función de conducir metodológicamente el Cabildo y cargar las actas de cada mesa de trabajo en la plataforma digital, asegurando la fidelidad de la información entregada por los participantes.

\section{El Comité de Sistematización}

La sistematización de los diálogos ciudadanos consistió en organizar la información y contenidos que producirán los distintos niveles de participación. Para dar garantía de autonomía, calidad y transparencia para la realización de esta tarea, se crea el Comité de Sistematización (Escudero, et.al. 2017). Este comité se constituyó como un cuerpo autónomo de especialistas en análisis y sistematización de contenidos. Es una entidad tripartita conformada por María Cristina Escudero de la Universidad de Chile, Ignacio Irarrázaval de la Pontificia Universidad Católica de Chile y Rodrigo Márquez del Programa de las Naciones Unidas para el Desarrollo (PNUD). El Comité tuvo la responsabilidad de diseñar e implementar la metodología de sistematización de las instancias participativas del proceso constituyente.

La metodología de sistematización siguió los más altos estándares de transparencia y trazabilidad para dar garantías de la fiabilidad y neutralidad de los reportes producidos. Se consideró procedimientos auditables en todas sus etapas por el Consejo Ciudadano de Observadores, así como de otros centros de estudio, organizaciones y ciudadanía en general. 


\section{Resultados de la Etapa Participativa}

La metodología de Convergencia Deliberativa, así como el diseño de una política pública centrada en el ciudadano y ciudadana, permitieron no sólo desarrollar un proceso participativo que involucró a más de 200.000 personas en sus distintas modalidades, si no que cumplió con uno de los objetivos fundamentales del proceso, que era, a partir de la implementación de una metodología específica, la ciudadanía pudiese llegar a acuerdos sobre temas constitucionales, y registrarlos.

\section{Una política que Sistematizó los resultados.}

La sistematización consistió en revisar y ordenar los resultados obtenidos en las distintas instancias de participación. Estuvo a cargo del Comité de Sistematización. En ella se describen los resultados de la participación en la Consulta Individual, Encuentros Locales, Cabildos Provinciales y Cabildos Regionales, para lvego codificar y organizar la información, asegurando que las opiniones sean recogidas fielmente en el informe de sistematización, cumpliendo altos estándares de transparencia, replicabilidad y trazabilidad.

La información se organizó cuantitativamente para dar cuenta de la frecuencia con que cada tema fue discutido, así como su nivel de acuerdo, acuerdo parcial y desacuerdo, y cualitativamente dará cuenta de los fundamentos que sustentan las elecciones de cada tema.

\section{Una política de datos Abiertos ${ }^{13}$}

El día 23 de agosto de 2016 se puso a disposición de la ciudadanía las bases de datos que reflejan lo escrito en las actas de todos los niveles de participación (Encuentros Locales, Cabildos Provinciales y Regionales), así como también los resultados de las Consultas Individuales. Los datos cumplen con los estándares internacionales de datos abiertos, y también dan cumplimiento a las recomendaciones del Consejo para la Transparencia en sus oficios No 8035/2016 y 6192/2016, y a los Acuerdos N 4, 12, 14 y 15 del Consejo Ciudadano de Observadores en estas materias.

Igualmente, en la Biblioteca Nacional están a disposición de la ciudadanía las actas correspondientes a los Cabildos Provinciales y Regionales. Las actas señaladas anteriormente, han debido ser anonimizadas, asegurando el resguardo de los datos personales de los participantes, cumpliendo de esta forma con la ley 19.628 y con las recomendaciones del Consejo para la Transparencia. El número de documentos revisados y anonimizados alcanza un total de 158.447.

13 La información se encuentra en: datos.gob.cl/dataset/proceso-constituyente-abierto-a-laciudadania 


\section{Perfil de participantes del proceso}

A continuación, se presentan los resultados estadísticos para cada uno de los niveles de participación (local, provincial y regional). En primer lugar, el total de participaciones según cada instancia de participación. Posteriormente, la participación a nivel nacional según género y rangos etarios, y el total de participación general por cada una de las regiones del país. Finalmente, los resultados de los debates donde las personas priorizaron siete conceptos por cada uno de los temas de discusión.

\section{Número de personas participantes por nivel de participación ${ }^{14}$}

Total, de Participantes: Corresponde a la identificación de cada persona, asociada a un RUT que participó en el proceso.

Figura 4.

Total, de participantes

\begin{tabular}{|l|l|}
\hline Etapas & Cantidad Participantes \\
\hline Solo contestó Consulta Individual & 74.790 \\
\hline Solo participó en ELA & 98.288 \\
\hline Solo participó en Cabildo Provincial & 5.321 \\
\hline Solo participó en Cabildo Regional & 4.477 \\
\hline Participantes en más de una instancia & 21.526 \\
\hline TOTAL & $\mathbf{2 0 4 . 4 0 2}$ \\
\hline
\end{tabular}

Fuente: Síntesis de resultados cuantitativos de la etapa participativa del Proceso Constituyente Abierto a la Ciudadanía

\section{Participación a nivel nacional según género y rangos etarios, y el total de participación general por cada una de las regiones del país}

Figura 5.

Participación según género y rango etario

\begin{tabular}{|l|l|l|l|l|l|l|l|l|}
\hline \multirow{2}{*}{ PARTICIPACIONES } & \multicolumn{2}{l|}{ GÉNERO } & \multicolumn{4}{l|}{ RANGO ETARIO } & \multirow{2}{*}{ TOTAL } \\
\cline { 2 - 10 } & $\mathbf{F}$ & $\mathbf{M}$ & $\mathbf{1 4 - 2 5}$ & $\mathbf{2 6 - 3 5}$ & $\mathbf{3 6 - 4 5}$ & $\mathbf{4 6 - 6 0}$ & $\mathbf{6 0}$ & \\
\hline $\mathrm{N}^{\circ}$ & 105.999 & 112.690 & $\mathbf{4 7 . 7 0 9}$ & 50.935 & 40.325 & $\mathbf{4 7 . 1 2 2}$ & 32.598 & 218.689 \\
\hline Porcentaje (\%) & $48,5 \%$ & $51,5 \%$ & $21,8 \%$ & $23,3 \%$ & $18,4 \%$ & $21,5 \%$ & $14,9 \%$ & $100 \%$ \\
\hline
\end{tabular}

Fuente: Síntesis de resultados cuantitativos de la etapa participativa del Proceso Constituyente Abierto a la Ciudadanía

\footnotetext{
14 Estos datos sólo incluyen las participaciones del proceso nacional. De forma paralela, la presidenta convocó a una consulta constituyente indígena, donde participaron más de 17.000 personas de los distintos pueblos indígenas de Chile (Bustamante, 2020).
} 
Figura 6.

Participación por región

\begin{tabular}{|l|l|l|}
\hline REGIÓN & N $^{\circ}$ PARTICIPANTES & \% DEL TOTAL \\
\hline Arica y Parinacota & 3.249 & 1,49 \\
\hline Tarapacá & 4.006 & 1,83 \\
\hline Antofagasta & 6.586 & 3,01 \\
\hline Atacama & 4.007 & 1,83 \\
\hline Coquimbo & 8.949 & 4,09 \\
\hline Valparaíso & 22.468 & 10,27 \\
\hline O'Higgins & 8.340 & 3,81 \\
\hline Maule & 10.432 & 4,77 \\
\hline Biobío & 17.119 & 7,83 \\
\hline La Araucanía & 8.566 & 3,92 \\
\hline Los Ríos & 4.710 & 2,15 \\
\hline Los Lagos & 9.036 & 4,13 \\
\hline Aisén & 3.180 & 1,45 \\
\hline Magallanes & 3.409 & 1,56 \\
\hline Metropolitana & 101.533 & 46,43 \\
\hline Extranjero & 218.689 & 1,00 \\
\hline Total & & \\
\hline
\end{tabular}

Fuente: Síntesis de resultados cuantitativos de la etapa participativa del Proceso Constituyente Abierto a la Ciudadanía 
Figura 7:

Tabla comparativa de las etapas de participación. Siete primeras menciones de principios y valores

\begin{tabular}{|c|c|c|c|c|c|c|c|c|c|c|c|}
\hline $\begin{array}{l}\text { Prela- } \\
\text { cion }\end{array}$ & $\begin{array}{l}\text { Consulta } \\
\text { Individual }\end{array}$ & $M^{*}$ & $\begin{array}{l}\text { Encuentros } \\
\text { Locales }\end{array}$ & $M^{*}$ & $A^{*}$ & $\begin{array}{l}\text { Cabildos } \\
\text { Provinciales }\end{array}$ & $M^{*}$ & $A^{*}$ & $\begin{array}{l}\text { Cabildos } \\
\text { Regionales }\end{array}$ & $M^{*}$ & $A^{*}$ \\
\hline 1 & Justicia & 47,6 & Justicia & 53,6 & 91.7 & Democracia & 98,0 & 87,3 & Democracia & 99.2 & 88,5 \\
\hline 2 & Igualdad & 37,8 & Democracia & 52,2 & 91,7 & Justicia & 95.4 & 88.8 & Igualdad & 97.1 & 81,8 \\
\hline 3 & Democracia & 37,5 & $\begin{array}{l}\text { Respeto/conservación } \\
\text { de la naturaleza } \\
\text { o medio ambiente }\end{array}$ & 52,1 & 92,6 & Igualdad & 95,3 & 80,4 & Descentralización & 96,3 & 78,9 \\
\hline 4 & $\begin{array}{l}\text { Respeto/conservación } \\
\text { de la naturaleza } \\
\text { o medio ambiente }\end{array}$ & 34.2 & Igualdad & 51,4 & 90,4 & $\begin{array}{l}\text { Respeto/conservación } \\
\text { de la naturaleza } \\
\text { o medio ambiente }\end{array}$ & 95,3 & 86,2 & Justicia & 96,3 & 89,6 \\
\hline 5 & Descentralización & 32,0 & Descentralización & 41,4 & 88,8 & Descentralización & 95,0 & 77.7 & $\begin{array}{l}\text { Respeto/conservación } \\
\text { de la naturaleza } \\
\text { o medio ambiente }\end{array}$ & 95.7 & 86.4 \\
\hline 6 & $\begin{array}{l}\text { Bien Común / } \\
\text { Comunidad }\end{array}$ & 24,8 & $\begin{array}{l}\text { Bien Común / } \\
\text { Comunidad }\end{array}$ & 38,3 & 89,7 & Respeto & 79,3 & 73,9 & Respeto & 83,9 & 75,2 \\
\hline 7 & Seguridad & 24,4 & Respeto & 34,2 & 91,0 & $\begin{array}{l}\text { Bien Común / } \\
\text { Comunidad. }\end{array}$ & 74,5 & 85,7 & $\begin{array}{l}\text { Bien Común / } \\
\text { Comunidad }\end{array}$ & 79,2 & 86,1 \\
\hline
\end{tabular}

$\mathbf{M}^{\hat{*}}=$ Porcentaje de Consultas Individuales, ELA y mesas de trabajo de Cabildos Provinciales y Regionales en que el concepto fue MENCIONADO $\mathbf{A}^{*}=$ Porcentajes de ACUERDO consignado en las Actas de ELAy mesas de trabajo de Cabildos Provinciales y Regionales.

Fuente: Informe Ejecutivo. Comité de Sistematización

Figura 8:

Tabla comparativa de las etapas de participación. Siete primeras menciones de derechos

\begin{tabular}{|c|c|c|c|c|c|c|c|c|c|c|c|}
\hline $\begin{array}{l}\text { Prela- } \\
\text { ción }\end{array}$ & $\begin{array}{l}\text { Consulta } \\
\text { Individual }\end{array}$ & $M^{*}$ & $\begin{array}{l}\text { Encuentros } \\
\text { Locales }\end{array}$ & $M^{*}$ & $A^{*}$ & $\begin{array}{l}\text { Cabildos } \\
\text { Provinciales }\end{array}$ & $M^{*}$ & $A^{k}$ & $\begin{array}{l}\text { Cabildos } \\
\text { Regionales }\end{array}$ & $M^{*}$ & $A^{*}$ \\
\hline 1 & A la educación & 64,1 & A la educación & 73.6 & 95,1 & A la educación & 97.4 & 93,0 & A la salud & 95,9 & 97,3 \\
\hline 2 & A la salud & 62,6 & A la salud & 73,0 & 96.1 & A la salud & 94,2 & 95,5 & $\begin{array}{l}\text { A la seguridad } \\
\text { social }\end{array}$ & 93.7 & 92,2 \\
\hline 3 & Igualdad ante la ley & 39,5 & Igualdad ante la ley & 37,0 & 93,6 & A vivienda digna & 86.4 & 89,3 & A la educación & 93.1 & 96,1 \\
\hline 4 & Al salario equitativo & 28,7 & A la vida & 34,4 & 80,2 & Igualdad ante la ley & 85,4 & 94,6 & A vivienda digna & 92.1 & 92,0 \\
\hline 5 & A vivienda digna & 27,4 & A vivienda digna & 33,4 & 93,7 & A la vida & 83,7 & 59,2 & Igualdad ante la ley & 90,8 & 99,5 \\
\hline 6 & $\begin{array}{l}\text { A la libertad } \\
\text { de expresión }\end{array}$ & 25,4 & $\begin{array}{l}\text { A la seguridad } \\
\text { social }\end{array}$ & 29.5 & 94,1 & $\begin{array}{l}\text { Respeto a la naturaleza } \\
\text { /medio ambiente }\end{array}$ & 83,7 & 85,6 & $\begin{array}{l}\text { Respeto a la naturaleza } \\
\text { /medio ambiente }\end{array}$ & 87,0 & 85,3 \\
\hline 7 & $\begin{array}{l}\text { Respeto a la naturaleza } \\
\text { /medio ambiente }\end{array}$ & 24,8 & $\begin{array}{l}\text { Respeto a la naturaleza } \\
\text { / medio ambiente }\end{array}$ & 27.9 & 92,3 & $\begin{array}{l}\text { A la seguridad } \\
\text { social }\end{array}$ & 82,5 & 93,7 & A la vida & 86.4 & 54.7 \\
\hline
\end{tabular}

$\mathbf{M}^{*}=$ Porcentaje de Consultas Individuales, ELA y mesas de trabajo de Cabildos Provinciales y Regionales en que el concepto fue MENCIONADO $\mathbf{A}^{*}=$ Porcentajes de ACUERDO consignado en las Actas de ELA y mesas de trabajo de Cabildos Provinciales y Regionales.

Fuente: Informe Ejecutivo. Comité de Sistematización 
Figura 9:

Tabla comparativa de las etapas de participación. Siete primeras menciones de deberes y responsabilidades

\begin{tabular}{|c|c|c|c|c|c|c|c|c|c|c|c|}
\hline $\begin{array}{l}\text { Prela- } \\
\text { cion }\end{array}$ & $\begin{array}{l}\text { Consulta } \\
\text { Individual }\end{array}$ & $M^{*}$ & $\begin{array}{l}\text { Encuentros } \\
\text { Locales }\end{array}$ & $M^{*}$ & $A^{*}$ & $\begin{array}{l}\text { Cabildos } \\
\text { Provinciales }\end{array}$ & $M^{*}$ & $A^{*}$ & $\begin{array}{l}\text { Cabildos } \\
\text { Regionales }\end{array}$ & $M^{*}$ & $A^{*}$ \\
\hline 1 & $\begin{array}{l}\text { Protección, promoción } \\
\text { y respeto a los DDHH } \\
\text { fundamentales }\end{array}$ & 68.6 & $\begin{array}{l}\text { Protección, promoción } \\
\text { y respeto a los DDHH } \\
\text { fundamentales }\end{array}$ & 81,0 & 96,5 & $\begin{array}{l}\text { Deberes de protección } \\
\text { y de conservación de la } \\
\text { naturaleza }\end{array}$ & 99,7 & 94,5 & $\begin{array}{l}\text { Deberes de protección } \\
\text { y de conservación de la } \\
\text { naturaleza }\end{array}$ & 100 & 96.4 \\
\hline 2 & $\begin{array}{l}\text { Deberes de protección } \\
\text { y de conservación de la } \\
\text { naturaleza }\end{array}$ & 63,3 & $\begin{array}{l}\text { Deberes de protección } \\
\text { y de conservación de la } \\
\text { naturaleza }\end{array}$ & 80,9 & 95,0 & $\begin{array}{l}\text { Respeto por } \\
\text { la Constitución }\end{array}$ & 91,8 & 88.7 & $\begin{array}{l}\text { Respeto por } \\
\text { la Constitución }\end{array}$ & 95,1 & 90,8 \\
\hline 3 & $\begin{array}{l}\text { Cumplimiento de las } \\
\text { leyes y normas }\end{array}$ & 60,1 & $\begin{array}{l}\text { Respeto por } \\
\text { la Constitución }\end{array}$ & 65.4 & 93,6 & $\begin{array}{l}\text { Protección, promoción } \\
\text { y respeto a los DDHH } \\
\text { fundamentales }\end{array}$ & 91,8 & 95,7 & $\begin{array}{l}\text { Protección y conservación } \\
\text { del patrimonio histórico } \\
\text { y cultural }\end{array}$ & 94,7 & 93,5 \\
\hline 4 & $\begin{array}{l}\text { Respeto de los } \\
\text { derechos de otros }\end{array}$ & 58,0 & $\begin{array}{l}\text { Protección y conservación } \\
\text { del patrimonio histórico } \\
\text { ycultural }\end{array}$ & 63,6 & 92,3 & $\begin{array}{l}\text { Respeto de los } \\
\text { derechos de otros }\end{array}$ & 89,6 & 90,3 & $\begin{array}{l}\text { Respeto de los } \\
\text { derechos de otros }\end{array}$ & 94,5 & 91,4 \\
\hline 5 & $\begin{array}{l}\text { Ejercicio legítimo } \\
\text { y no abusivo de los } \\
\text { derechos }\end{array}$ & 51,2 & $\begin{array}{l}\text { Respeto de los } \\
\text { derechos de otros }\end{array}$ & 62,2 & 83,8 & $\begin{array}{l}\text { Protección y conservación } \\
\text { del pattrimonio histórico } \\
\text { y cultural }\end{array}$ & 88,1 & 92,7 & $\begin{array}{l}\text { Cumplimiento de las } \\
\text { leyes y normas }\end{array}$ & 94,3 & 86,2 \\
\hline 6 & $\begin{array}{l}\text { Protección y conservación } \\
\text { del patrimonio histórico } \\
\text { ycultural }\end{array}$ & 46,2 & $\begin{array}{l}\text { Cumplimiento de las } \\
\text { leyes y normas }\end{array}$ & 52,6 & 91,8 & $\begin{array}{l}\text { Cumplimiento de las } \\
\text { leyes y normas }\end{array}$ & 86,9 & 86,7 & $\begin{array}{l}\text { Protección, promoción } \\
\text { y respeto a los DDHH } \\
\text { fundamentales }\end{array}$ & 93,1 & 98,5 \\
\hline 7 & Responsabilidad & 41,4 & $\begin{array}{l}\text { Ejercicio legítimo } \\
\text { y no abusivo de los } \\
\text { derechos }\end{array}$ & 49.6 & 91.9 & $\begin{array}{l}\text { Ejercicio legítimo } \\
\text { y no abusivo de los } \\
\text { derechos }\end{array}$ & 80,9 & 87.0 & $\begin{array}{l}\text { Ejercicio legítimo } \\
\text { y no abusivo de los } \\
\text { derechos }\end{array}$ & 87,0 & 86.7 \\
\hline
\end{tabular}

$\mathbf{M}^{*}=$ Porcentaje de Consultas Individuales, ELA y mesas de trabajo de Cabildos Provinciales y Regionales en que el concepto fue MENCIONADO $A^{*}=$ Porcentajes de ACUERDO consignado en las Actas de ELA y mesas de trabajo de Cabildos Provinciales y Regionales.

Fuente: Informe Ejecutivo. Comité de Sistematización

Figura 10:

Tabla comparativa de las etapas de participación. Siete primeras menciones de instituciones

\begin{tabular}{|c|c|c|c|c|c|c|c|c|c|c|c|}
\hline $\begin{array}{l}\text { Prela- } \\
\text { ción }\end{array}$ & $\begin{array}{l}\text { Consulta } \\
\text { Individual }\end{array}$ & $M^{*}$ & $\begin{array}{l}\text { Encuentros } \\
\text { Locales }\end{array}$ & $M^{*}$ & $A^{\frac{2}{*}}$ & $\begin{array}{l}\text { Cabildos } \\
\text { Provinciales }\end{array}$ & $M^{*}$ & $A^{*}$ & $\begin{array}{l}\text { Cabildos } \\
\text { Regionales }\end{array}$ & $M^{*}$ & $A^{*}$ \\
\hline 1 & $\begin{array}{l}\text { Plebiscitos, referendos } \\
\text { y consultas }\end{array}$ & 48,1 & $\begin{array}{l}\text { Plebiscitos, referendos } \\
\text { y consultas }\end{array}$ & 69,5 & 94,3 & $\begin{array}{l}\text { Plebiscitos, referendos } \\
\text { y consultas }\end{array}$ & 98,6 & 94,9 & $\begin{array}{l}\text { Plebiscitos, referendos } \\
\text { y consultas }\end{array}$ & 99,8 & 95,3 \\
\hline 2 & $\begin{array}{l}\text { Poder Judicial } \\
\text { (estructura y funciones) }\end{array}$ & 43,6 & $\begin{array}{l}\text { Congreso o Parlamento } \\
\text { (estructuray funciones) }\end{array}$ & 50,5 & 89,6 & $\begin{array}{l}\text { Defensor del Pueblo / } \\
\text { Ciudadano }\end{array}$ & 87,7 & 87,6 & $\begin{array}{l}\text { Congreso o Parlamento } \\
\text { (estructura y funciones) }\end{array}$ & 96,7 & 79,2 \\
\hline 3 & $\begin{array}{l}\text { Congreso o Parlamento } \\
\text { (estructura y funciones) }\end{array}$ & 41,2 & $\begin{array}{l}\text { Defensor del Pueblo / } \\
\text { Ciudadano }\end{array}$ & 46,3 & 91,4 & $\begin{array}{l}\text { Congreso o Parlamento } \\
\text { (estructuray funciones) }\end{array}$ & 87,3 & 79,9 & $\begin{array}{l}\text { Defensor del Pueblo / } \\
\text { Ciudadano }\end{array}$ & 90,8 & 87,9 \\
\hline 4 & $\begin{array}{l}\text { Presidencia de } \\
\text { la República }\end{array}$ & 40,5 & $\begin{array}{l}\text { Poder Judicial } \\
\text { (estructuray funciones) }\end{array}$ & 40,5 & 92,6 & $\begin{array}{l}\text { Poder Judicial } \\
\text { (estructura y funciones) }\end{array}$ & 82,8 & 91,0 & $\begin{array}{l}\text { Poder Judicial } \\
\text { (estructura y funciones) }\end{array}$ & 86,2 & 89,8 \\
\hline 5 & $\begin{array}{l}\text { Cambio o reforma } \\
\text { constitucional }\end{array}$ & 33,6 & $\begin{array}{l}\text { Fuerzas } \\
\text { Armadas }\end{array}$ & 39,4 & 86,7 & $\begin{array}{l}\text { Fuerzas } \\
\text { Armadas }\end{array}$ & 78,0 & 66,6 & $\begin{array}{l}\text { Asamblea } \\
\text { Constituyente }\end{array}$ & 80,9 & 80,8 \\
\hline 6 & $\begin{array}{l}\text { Defensor del Pueblo / } \\
\text { Ciudadano }\end{array}$ & 32,6 & $\begin{array}{l}\text { Gobierno } \\
\text { Regional }\end{array}$ & 37,1 & 90,8 & $\begin{array}{l}\text { Cobierno } \\
\text { Regional }\end{array}$ & 62,8 & 89,5 & $\begin{array}{l}\text { Fuerzas } \\
\text { Armadas }\end{array}$ & 77,6 & 59,8 \\
\hline 7 & $\begin{array}{l}\text { Cobierno } \\
\text { Regional }\end{array}$ & 31,0 & $\begin{array}{l}\text { Régimen de Gobierno } \\
\text { presidencial/semi-pre- } \\
\text { sidencial / Parlamento }\end{array}$ & 35,9 & 78,4 & $\begin{array}{l}\text { Asamblea } \\
\text { Constituyente }\end{array}$ & 60,1 & 85,8 & $\begin{array}{l}\text { Cobierno } \\
\text { Regional }\end{array}$ & 76,8 & 88,6 \\
\hline
\end{tabular}

$\mathbf{M}^{*}=$ Porcentaje de Consultas Individuales, ELAy mesas de trabajo de Cabildos Provinciales y Regionales en que el concepto fue MENCIONADO $\mathbf{A}^{*}=$ Porcentajes de ACUERDO consignado en las Actas de ELAy mesas de trabajo de Cabildos Provinciales y Regionales.

Fuente: Informe Ejecutivo. Comité de Sistematización 


\section{Evaluación del proceso: seguidores y detractores}

Como en todo proceso político de cambio, el Proceso Constituyente Abierto a la Ciudadanía tuvo seguidores y detractores. Las restricciones propias del contexto político e institucional que enfrentaba el gobierno de Michelle Bachelet para avanzar en un proceso de cambio constitucional, sentido por la ciudadanía y rechazado por las elites, constituyó una de las grandes paradojas del proceso (Couso, 2018).

El Proceso Constituyente Abierto a la Ciudadanía efectuado en Chile durante 2016, ha sido observado y estudiado durante los últimos años (OCDE, 2017; Soto y Welp, 2019, Heiss, 2016). Algunos se han referido a que la etapa participativa no fue un proceso de deliberación constituyente por no darse el denominado momento constituyente (Heiss, 2016), otros han señalado que los procesos constituyentes son en si procesos, y que una vez que comienzan en general tienden a avanzar, aunque a veces sea con interrupciones (Escudero, 2018). Soto y Welp (2017) han descrito el proceso chileno como uno de apertura participativa, y no constituyente, por no existir instrumentos formales que obliguen al tratamiento. Se ha señalado anteriormente, que el diseño del proceso consideraba al Congreso como actor clave en las siguientes etapas, luego de la participación. El caso de Islandia muestra dificultades similares al caso chileno (Landemore, 2015).

A nivel internacional, la etapa participativa del Proceso Constituyente se conformó como uno de los ejercicios de participación no electoral más exitoso, uno de los mayores niveles de participación ciudadana a nivel mundial, en procesos de cambio constitucional, tal como se demuestra en la Figura 11:

Figura 11:

Participación Ciudadana en Procesos de Cambio Constitucional15

\begin{tabular}{|c|c|c|c|}
\hline País & Modelo & Participación & $\begin{array}{c}\text { Tasa de } \\
\text { participación } \\
\text { (en relación con } \\
\text { población total) }\end{array}$ \\
\hline Chile & $\begin{array}{c}\text { Etapa participativa en tres } \\
\text { niveles: local, provincial y } \\
\text { regional. }\end{array}$ & $\begin{array}{c}204.402 \text { participantes } \\
\text { a nivel nacional }\end{array}$ & $1,13 \%$ \\
\hline Colombia & $\begin{array}{c}1580 \text { mesas de trabajo forma- } \\
\text { das a lo largo del país, en los 3 } \\
\text { meses previos a la formación } \\
\text { de la asamblea. }\end{array}$ & $\begin{array}{c}\text { El máximo era } 30 \\
\text { miembros, pero se } \\
\text { calcula una partici- } \\
\text { pación promedio de } \\
10 \text { a } 15\end{array}$ & $0,06 \%$ \\
\hline
\end{tabular}

15 En el Scan Report de OCDE 2017 sobre la Ełapa Participativa, se señala que en términos comparados el nivel de participación en Chile ha sido el más alto considerando el porcentaje de población que representa del total de población, llegando a un 1,13\%. 


\begin{tabular}{|c|c|c|c|}
\hline Ecuador & $\begin{array}{l}10 \text { mesas, estas mesas } \\
\text { recorrieron el país organizando } \\
\text { espacios de discusión, para } \\
\text { recabar propuestas de la } \\
\text { sociedad civil en cada uno de } \\
\text { los temas definidos }\end{array}$ & $\begin{array}{c}70.000 \text { personas } \\
\text { aproximadamente. }\end{array}$ & $0,5 \%$ \\
\hline Islandia & $\begin{array}{l}\text { Foro nacional, se discute la } \\
\text { necesidad de una nueva cons- } \\
\text { titución, mediante ciudadanos } \\
\text { que representen la diversidad } \\
\text { territorial y de género }\end{array}$ & 950 ciudadanos & $\begin{array}{c}0,3 \% \text { para los en- } \\
\text { cuentros }\end{array}$ \\
\hline Sudáfrica & $\begin{array}{l}\text { Mesas de trabajos, talleres y } \\
\text { charlas Todos los sudafricanos } \\
\text { fueron invitados a compartir sus } \\
\text { reflexiones, enviar sus aporta- } \\
\text { ciones por escrito, interviniendo } \\
\text { en los actos públicos, llamando } \\
\text { a la línea abierta de la AC } \\
\text { creada para estos efectos, o } \\
\text { bien por internet. También se } \\
\text { generó un trabajo para incluir } \\
\text { a los habitantes de zonas ex- } \\
\text { tremas y con bajos índices de } \\
\text { alfabetización }\end{array}$ & $\begin{array}{c}95.000 \text { participantes } \\
1.700 .000 \text { aportacio- } \\
\text { nes }\end{array}$ & $0,2 \%$ \\
\hline
\end{tabular}

Fuente: Elaboración propia a partir de datos de la División de Estudios, Ministerio Secretaría General de la Presidencia (2017), PNUD (2014) y OCDE (2017).

La OCDE ha señalado que el proceso chileno ha dejado aprendizajes claves para que la participación pública se incorpore en la generación de políticas de gobierno. Sostenido en estas claves, indicó que los principios de la Ełapa Participativa sirven como marco analítico para la implementación de mecanismos de consulta para los países de la OCDE (OECD, 2017).

De parte de los detractores, se ha destacado como positivo el diseño de la metodología de Convergencia Deliberativa, y se ha criticado con fuerza la falta de capacidad política de llevar a término el proceso por parte del gobierno de Bachelet, decretando el fracaso del proceso (Couso, 2018; Heiss, 2016). Es importante destacar que la evaluación de las políticas públicas se mide con relación a los objetivos propuestos por dicha política, y a la capacidad de diagnosticar un problema y su dimensión. Lo cierto, es que, así como fue el caso de Islandia en 2008, definido como un "experimento radical de innovación democrática" (Landemore, 2015), los procesos participativos enfrentan importantes resistencias entre sectores conservadores que se oponen al cambio. Esos sectores tanto en Chile, como en Islandia estuvieron en la posición de limitar el avance del proceso participativo en un cambio real a la constitución. 


\section{Conclusiones}

Este estudio ha revisado los fundamentos de la Etapa Participativa del Proceso Constituyente, considerando el Programa de Gobierno de Michelle Bachelet (2013), y las definiciones conceptuales y metodológicas del mecanismo de cambio constitucional en Chile a través de la Convergencia Deliberativa. Ha analizado las condiciones contextuales (condiciones sociales de demanda de cambio constitucional), institucionales (restricciones legales y oportunidades de diseño de la política pública) y de actores políticos y sociales asociados al proceso (actores involucrados en la estructura de toma de decisiones: gobierno, CCO, Comité de Sistematización, Facilitadores del Diálogo; así como el perfil sociodemográfico de quienes participaron del proceso participativo nacional).

El desafío durante el mandato presidencial de Michelle Bachelet ${ }^{16}$, fue generar las condiciones necesarias para la participación, asegurando la incidencia de la opinión ciudadana en el proyecto de cambio constitucional elaborado a partir de las Bases Ciudadanas (Encuentro) y avanzar en la posibilidad constitucional de este cambio en el Congreso (Deliberación). Por lo anterior, como resultado del proceso la presidenta deja su legado en: a) las Bases Ciudadanas producto de un proceso amplio de deliberación ciudadana, b) proyecto de reforma al Capítulo XV de la Constitución enviado en abril de 2017, donde propone

la Convención Constitucional, y c) un texto completo de nueva Constitución basado en los diálogos ciudadanos y enviado al Congreso en marzo de 2018.

Debido a la ausencia de un acuerdo político amplio por el cambio constitucional durante el gobierno de la presidenta Michelle Bachelet (2014-2018), que acompañara el amplio acuerdo social por el cambio constitucional; y al cambio de gobierno en marzo de 2018, donde asume como presidente Sebastián Piñera, el proceso constituyente queda suspendido.

De lo anterior, puede señalarse que el proceso constituyente en curso en Chile tiene sus antecedentes en el origen dictatorial de la Constitución de 1980, y que a pesar de las múltiples e importantes reformas que ha tenido, no ha logrado dotarse de legitimidad. Esto se ve profundizado por el cambio de la sociedad chilena, cambio que se expresa ampliamente en los resultados de la etapa participativa del proceso constituyente. La priorización de valores y principios, derechos y deberes, e instituciones del Estado, muestra una sociedad que pone en valor la justicia social, la democracia, los derechos sociales y un poder político distribuido entre los distintos actores de la sociedad. Esos aspectos valorados por la sociedad no están presentes en la actual Constitución, lo que explica el desfase entre ciudadanía e instituciones, y la creciente desconfianza hacia el sistema político.

16 En Chile el período presidencial tiene una duración de cuatro (4) años, sin reelección inmediata. 


\section{Bibliografía}

Atria, F., Salgado, C. y Wilenmann, J. (2017). Democracia y neutralización. Origen, desarrollo y solución de la crisis constitucional. Santiago, Chile: Editorial LOM.

Atria, F. (2013). La Constitución Tramposa. Santiago, Chile: Editorial LOM.

Biblioteca del Congreso Nacional. «Historia de la Ley de reforma constitucional No 21.200». https://www.bcn.cl/historiadelaley/nc/historia-de-la-ley/771 1/

Bobbio, N. (1986). Democracia representativa y democracia directa. En El futuro de la democracia, (pp. 32-50). Madrid, España: Fondo de Cultura Económica

Bonar, A. W. K. (2017). By the people, for the people linking democratic theory to constitution-making and designing an effective mechanism for public participation in Liberia's constitutional reform process (Order No. 10622290). Available from ProQuest One Academic. (1953259656). Retrieved from https://searchproquest-com.ezproxy.usach.cl/docview/1953259656? accountid=45394

Bustamante, M. (2020). El reconocimiento constitucional de los pueblos indígenas: los desafíos para el proceso constituyente. En, Figueroa, P \& Jordán, T. 7 propuestas para la nueva Constitución de Chile. Santiago, Chile: Editorial USACH.

Contiades, X y Fotiadou A. (2016). Participatory Constitutional Change: The People as Amendres of the Constitution. Nueva York, Estados Unidos: Routdlege.

Couso, J. (2018). Annex. Reflection on Latin American Constitution Building from a Chilean perspective. En, IDEA (2018) Constitution Building Processes in Latin America. International IDEA Discussion Paper, (3)

Cristi, R. y Ruíz-Tagle, P. (2006). La república en Chile. Teoría y práctica del constitucionalismo. Santiago, Chile: Editorial LOM.

Cunill, N. (1991.) Participación ciudadana y perspectivas para la democratización de los Estados Latinoamericanos. Caracas, Venezuela: CLAD, Centro Latinoamericano de Administración para el Desarrollo.

De la República. (8 de noviembre de 2013). Recuperado el noviembre de 2020, de Republicanos: https://blog.delarepublica.cl/documentos/programas-de-gobierno-candidatos-presidenciales-chile-2014-2018/

Elster, J. (Ed.). (1998). Deliberative Democracy (Cambridge Studies in the Theory of Democracy). Cambridge, UK: Cambridge University Press. doi:10.1017/ CBO9781139175005

Escudero, M. C. (2018). Efectos del proceso constituyente en el éxito del reemplazo constitucional. Unpublished doctoral dissertation. Santiago, Chile: Universidad Católica de Chile.

Escudero, M.C., Irarrázaval, I. y Márquez, R. (2017). Informe Ejecutivo Sistematización de la etapa participativa del proceso constituyente abierto a la ciudadanía. Santiago, Chile: Ministerio Secretaria General de la Presidencia.

Eyzaguirre, N. Figueroa, P. y Jordán, T. (Autores) (2020). Crisis del Híper- Presidencialismo chileno y nueva constitución: ¿̇cambio al régimen político? Santiago, Chile: FLACSO-Chile.

Ferrajoli, L. Entrevista en Expertos en Estudio: El rol de las constituciones. Recuperado de: https://www.youtube.com/watch? v=S1ykTjUqcR8

Figueroa, P. y Jordán, T. (2017). El Proceso Constituyente Abierto a la Ciudadanía: el modelo chileno de cambio constitucional. Hemiciclo, (16) 46-59.

(2017a) «La Ruta Hacia Una Mejor Democracia». En Reformas Políticas En Chile 2014-2016. Análisis Y Evaluación De Las Modificaciones Al Sistema Político Chileno Durante El Gobierno De La Presidenta Michelle Bachelet editado por Ministerio Secretaría General de la Presidencia, 12-52. Santiago, Chile: MINSEGPRES.

Fuentes, C. (2012) El Pacto: poder, constitución y prácticas políticas. Santiago, Chile: Ediciones UDP, 2013.

Gargarella, R. (2015). El "nuevo constitucionalismo latinoamericano". Estudios Sociales. Revista Universitaria Semestral, 48 (1), 2015, 169-174. Recuperado de https://bibliotecavirtual.unl.edu.ar/publicaciones/index.php/EstudiosSociales/article/view/5105

Garretón, M.A. (1995). Hacia una nueva era política: estudios sobre las democratizaciones. Santiago, Chile: FCE

Ginsburg, T; Zachary, E y Blount, J. (2009). «Does the process of constitution making matter? II, Annual Reviews, (5), 201-223.Recuperado de https://www.annual- 
reviews.org/doi/abs/10.1146/annurev.lawsocsci.4.110707.172247

Gluck, J \& Brandt, M. (2015). Participatory and Inclusive Constitution Making, (5). Washington D.C, United States: Institute of Peace

Gobierno de Chile. (2017). Memoria Etapa Participativa Proceso Constituyente Abierto a la Ciudadanía.

Habermas, J. (2010). Facticidad y validez. Madrid, España: Editorial Trotta.

(2005). Tres modelos de democracia. Sobre el concepto de una política deliberativa, Polis, Revista Latinoamericana, 4(10),113-122. Recuperado de http://journals.openedition.org/polis/7473

Heiss, C. (2016). "Soberanía popular y 'momento constituyente' en el debate sobre cambio constitucional en Chile". Anales de la Universidad de Chile. 7(10), 109-125.Recuperado de https://anales.uchile.cl/index.php/ANUC/article/ view/43145

IDEA.(2020). Annual Review on Constitution Building 2018. IDEA International. https://doi.org/10.31752/idea.2020.7

Jordán, T. Y Figueroa, P. (2020). El proceso constituyente abierto a la ciudadanía: El modelo chileno de cambio constitucional. En, Araya, R. Doscientas mil voces: Ecos y aprendizajes del proceso constituyente del gobierno de Michelle Bachelet. Santiago, Chile: Ediciones Abierta.

Jordán, T., Figueroa,P., Araya, R. y Gómez, C. (2016). Guía Metodológica Para la Etapa Participativa Territorial. Santiago, Chile: Ministerio Secretaría General de la Presidencia.

Jordán, T. (2015) Siete Tesis sobre una Nueva Constitución y una Propuesta. En Ideas para el Debate N 3. Santiago, Chile: Clapes-UC Universidad Católica de Chile.

(2014). Por qué en verdad es justo y necesario, es nuestro deber darnos una Nueva Constitución. En Jordán, T. y Tórtora H. Estudios para una nueva Constitución. Santiago, Chile: Editorial Metropolitana.

Landemore, H. (2015), Inclusive Constitution Making. The Journal of Political Philosophy, 23 (2) 166-191.doi: https://doi.org/10.1111/jopp.12032

Mardones, R. Y Toro, S. (2014). Chile frente al cambio de ciclo Participación y preferencias electorales en las elecciones chilenas de 2013. Revista Nueva Sociedad (249). Recuperado de www.nuso.org.

Negretto, G. (2015). La política del cambio constitucional en América Latina. Ciudad de México, México: FCE/CIDE.

OCDE (Organización para la Cooperación y el Desarrollo Económicos). (2017) OECD Public Governance Review: Chile. Scan Report on the citizen participation in the constitutional process. Paris, France: OECD Public Governance Review.

. (Organización para la Cooperación y el Desarrollo Económicos). (2001) Participación Ciudadana. Manual de la OCDE sobre información, consulta y participación e la elaboración de las políticas públicas. Paris, France: OECD.

OECD (2005), Evaluating Public Participation in Policy Making. Paris, France: OECD Publishing. Recuperado de https://doi.org/10.1787/9789264008960-en.

PNUD (Programa de las Naciones Unidas para el Desarrollo). (2015) Mecanismos de cambio constitucional en el mundo. Análisis desde la experiencia comparada. Santiago, Chile: Programa de las Naciones Unidas para el Desarrollo.

.(Programa de las Naciones Unidas para el Desarrollo). $\left(2015^{a}\right)$. Desarrollo Humano en Chile. Los tiempos de la politización. Santiago, Chile: Programa de las Naciones Unidas para el Desarrollo.

(Programa de las Naciones Unidas para el Desarrollo). (2014). Auditoría a la Democracia. Mas y mejor democracia para un Chile inclusivo. Santiago, Chile: Programa de las Naciones Unidas para el Desarrollo.

Sennet, R. (2012). Juntos: rituales, placeres y política de cooperación, Barcelona, España: Editorial Anagrama.

Soto, F, y Welp, J. (2019). Más allá de modas y cortinas de humo: la deliberación ciudadana en cambios constitucionales. Revista Española de Ciencia Política, (50),13-41. doi 10.21308/recp.50.01

. (2017). Los diálogos ciudadanos. Chile ante el giro deliberativo. Santiago, Chile: LOM.

Trazabilidad de las Bases Ciudadanas en el proyecto de nueva Constitución de la presidenta Michelle Bachelet. https://public.tableau.com/profile/jose. 
chavez\#!/vizhome/PlataformalnfograficaPROCO/Introduccin

Welp, Y. (2017) La participación ciudadana como compromiso democrático. Revista Mexicana de Derecho Electoral, (10), 97-121. doi:http://dx.doi. org/10.22201/iij.24487910e.2016.10.11122. 